\title{
Scanning Electron Microscopy of the Surfaces of Ion Implanted SiC
}

\author{
Johan B Malherbe ${ }^{1 *}$, NG van der Berg ${ }^{1}$, RJ Kuhudzai ${ }^{1}$, TT Hlatshwayo ${ }^{1}$, TT \\ Thabethe $^{1}$, OS Odutemowo ${ }^{1}, \mathrm{CC}_{\text {Theron }}{ }^{1}$, E Friedland $^{1}$, AJ Botha $^{2}$, E Wendler $^{3}$ \\ ${ }^{1}$ Department of Physics, University of Pretoria, Pretoria, 0002, South Africa \\ ${ }^{2}$ Laboratory for Microscopy \& Microanalysis, University of Pretoria, Pretoria, 0002, South Africa \\ ${ }^{3}$ Institut für Festkörperphysik, Friedrich-Schiller-Universität Jena, 07743 Jena, Germany
}

\begin{abstract}
This paper gives a brief review of radiation damage caused by particle (ions and neutrons) bombardment in $\mathrm{SiC}$ at different temperatures, and its annealing, with an expanded discussion on the effects occurring on the surface. The surface effects were observed using SEM (scanning electron microscopy) with an in-lens detector and EBSD (electron backscatter diffraction). Two substrates were used, viz. single crystalline $6 \mathrm{H}-\mathrm{SiC}$ wafers and polycrystalline $\mathrm{SiC}$, where the majority of the crystallites were $3 \mathrm{C}-\mathrm{SiC}$. The surface modification of the $\mathrm{SiC}$ samples by $360 \mathrm{keV}$ ion bombardment was studied at temperatures below (i.e. room temperature), just at (i.e. $350{ }^{\circ} \mathrm{C}$ ), or above (i.e. $600{ }^{\circ} \mathrm{C}$ ) the critical temperature for amorphization of SiC. For bombardment at a temperature at about the critical temperature an extra step, viz. post-bombardment annealing, was needed to ascertain the microstructure of bombarded layer. Another aspect investigated was the effect of annealing of samples with an ion bombardment-induced amorphous layer on a $6 \mathrm{H}-\mathrm{SiC}$ substrate. SEM could detect that this layer started to crystalize at $900{ }^{\circ} \mathrm{C}$. The resulting topography exhibited a dependence on the ion species. EBSD showed that the crystallites forming in the amorphized layer were $3 \mathrm{C}-\mathrm{SiC}$ and not $6 \mathrm{H}-\mathrm{SiC}$ as the substrate. The investigations also pointed out the behaviour of the epitaxial regrowth of the amorphous layer from the $6 \mathrm{H}-\mathrm{SiC}$ interface.
\end{abstract}

- johan.malherbe@up.ac.za

Keywords: Nuclear materials, photovoltaic materials, SiC, SEM, radiation damage, damage annealing, implantation, ion bombardment, microstructure, topography, morphology, epitaxy

\section{INTRODUCTION}

Many of present applications and future applications of $\mathrm{SiC}$ is based on two of its key properties - it is one of the hardest natural materials, with a hardness of around $9.2-$ 9.3 Mohs [1], and it has the ability to retain most of its properties at high temperatures - it decomposes significantly in vacuum only at about $1700^{\circ} \mathrm{C}$ [2]. There are two applications of $\mathrm{SiC}$, where particle bombardment is a fundamental step in their operation. SiC is a wide band-gap semiconductor and can, therefore, be used in high temperature electronic devices. Doping of the $\mathrm{SiC}$ is usually done by ion bombardment and annealing. SiC is also used as a coating layer covering the fuel elements of the next generation of nuclear 
power plants because $\mathrm{SiC}$ is diffusion barrier for radioactive fission products [3, 4]. This diffusion barrier property will prevent the escape of radioactive fission products into the environment during an accident in such a nuclear reactor.

For both these two applications the radiation damage properties of $\mathrm{SiC}$ need to be investigated. Because there is a large difference between the covalent radii of the silicon and carbon atoms, $\mathrm{SiC}$ has, for the common semiconductor materials, a fairly large iconicity value of 0.475 on the Garcia- Cohen scale (Phillips 0.177 and Pauling 0.11) with charge transfer to the carbon atom [5]. Because its iconicity is larger than most of the common semiconductors, it is more radiation resistant than those semiconductors. This results in potential electronic and sensor applications in a radiation environment [6, 7]. However, $\mathrm{SiC}$ is still mainly a covalent bonded material ( $88 \%$ covalency and $12 \%$ ionic). This means that it is hard to anneal radiation damaged SiC, with only very high temperatures (1500 ${ }^{\circ} \mathrm{C}$ and higher) being reported as successful to anneal a completely bombardment-induced amorphous $\mathrm{SiC}$ layer on $6 \mathrm{H}-\mathrm{SiC}[3,8,9]$.

Most of the radiation damage and annealing studies of $\mathrm{SiC}$ have employed either transmission electron microscopy (TEM) or Rutherford backscattering/channeling. In this paper we report on ion bombardment-induced radiation damage of $6 \mathrm{H}-\mathrm{SiC}$ and polycrystalline $\mathrm{SiC}$ (predominantly $3 \mathrm{C}-\mathrm{SiC}$ crystallites) using $\mathrm{SEM}$ (scanning electron microscopy). This means that the results mainly pertain to processes occurring on the surface of these materials. We shall report on the effect of ion bombardment at room temperature and at $350{ }^{\circ} \mathrm{C}$ and $600{ }^{\circ} \mathrm{C}$ on these surfaces, and also annealing of $6 \mathrm{H}-\mathrm{SiC}$ with a top amorphized layer caused by ion bombardment at room temperature.

\section{EXPERIMENTAL}

6H-SiC (from Intrinsic Semiconductors ${ }^{\circledR}$ and from Pam-Xiamen) and polycrystalline $\mathrm{SiC}$ - predominantly 3C-SiC crystallites - (from Valley Design Corporation ${ }^{\circledR}$ ) samples were investigated by field emission scanning electron microscopy (FEG-SEM) employing a Zeiss Ultra 55 instrument fitted with the usual SEM detectors and an in-lens detector. In this paper, unless specifically mentioned, mostly images taken at $2 \mathrm{kV}$ in the in-lens mode are shown.

Various ions, all with an energy of $360 \mathrm{keV}$, were implanted into the $\mathrm{SiC}$ samples at an incidence angle of $7^{\circ}$ to fluences of either $1 \times 10^{16}$ or $2 \times 10^{16} \mathrm{~cm}^{-2}$. A dose rate of about $5 \times 10^{12}$ $\mathrm{cm}^{-2} \mathrm{~s}^{-1}$ was used. Notwithstanding this relatively low rate, temperature of the samples implanted at room temperature increased to about $50^{\circ} \mathrm{C}$ during the bombardment process, which will be denoted as bombarded at room temperature. To investigate the effect of substrate temperature during ion bombardment, some samples were implanted at $350^{\circ} \mathrm{C}$ and some at $600{ }^{\circ} \mathrm{C}$. Some samples were vacuum annealed in a computer controlled Webb graphite furnace for different periods at temperatures ranging from 800 up to $1600{ }^{\circ} \mathrm{C}$. The base pressure prior to annealing was in the range $10^{-6}-10^{-7}$ mbar. During annealing, the pressure sharply increased to a maximum of $5 \times 10^{-5}$ mbar and then decreased to the low to middle $10^{-6}$ mbar range.

\section{RESULTS AND DISCUSSION}

As was mentioned in the previous section (Experimental) in this paper only SEM images taken in the in-lens mode, are shown. The in-lens detector gives SEM images showing defects present in the samples but at the expense of topographic detail, which is the forte of the conventional SEM detector. Crystallographic detail (an important aspect in this paper) also becomes more distinguishable in the in-lens mode. In Figure 1 a normal secondary electron SEM detector image (Figure 1 (a)) and also an in-lens SEM image (Figure 1 (b)) of the same area of a 


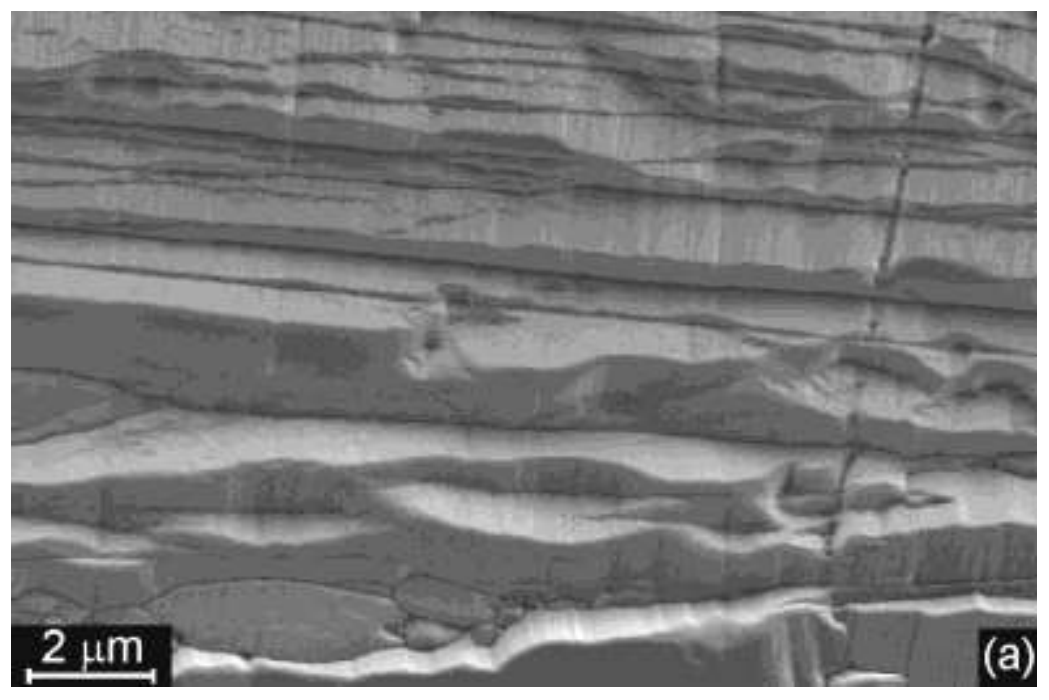

(a)

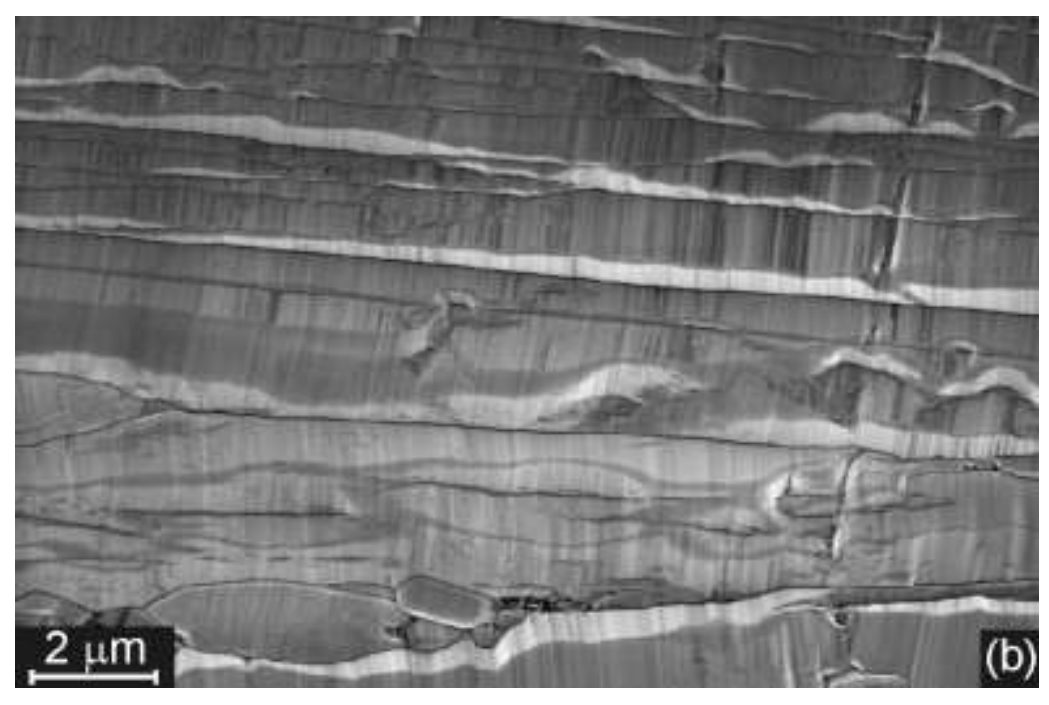

(b)

Figure 1. (a) A normal SEM image showing the facets of the different crystallites and (b) an in-lens image showing stacking faults and microstwins in the crystallites, of the same area of a polycrystalline SiC sample.

polycrystalline $\mathrm{SiC}$ sample are shown. In the normal SEM image the topography of the sample is clear to see. In contrast, the topography is much less pronounced in the in-lens image but many lines appear in the crystallites. These defect lines are due to twins and stacking faults, which are extremely common in SiC due to its plethora of polytypes [10]. The reason for the polytype formation in $\mathrm{SiC}$ (and consequent line and plane defects) lies in the very small differences in the total energy of formation between the common polytypes, viz. of the order of $\mathrm{O}(1) \mathrm{meV} / \mathrm{atom}$, or even less [11].

Radiation damage caused by particle bombardment in $\mathrm{SiC}$ has recently been reviewed [3]. 


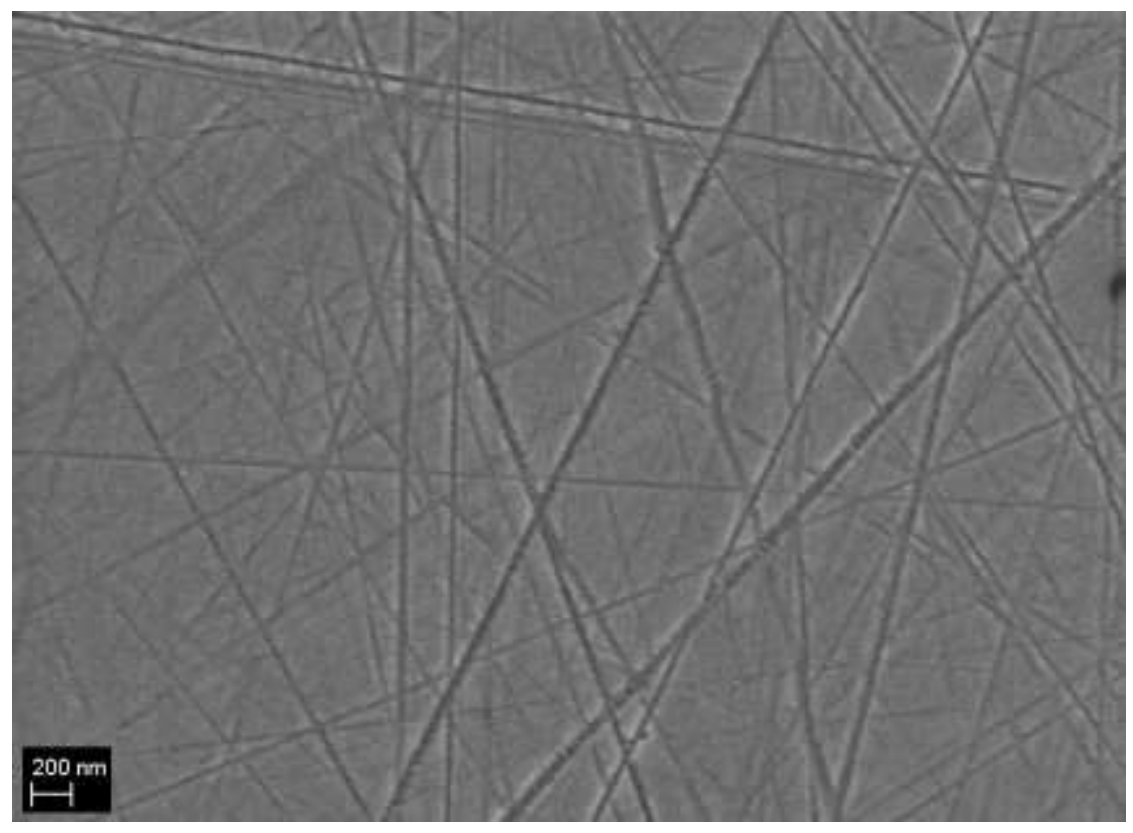

(a)

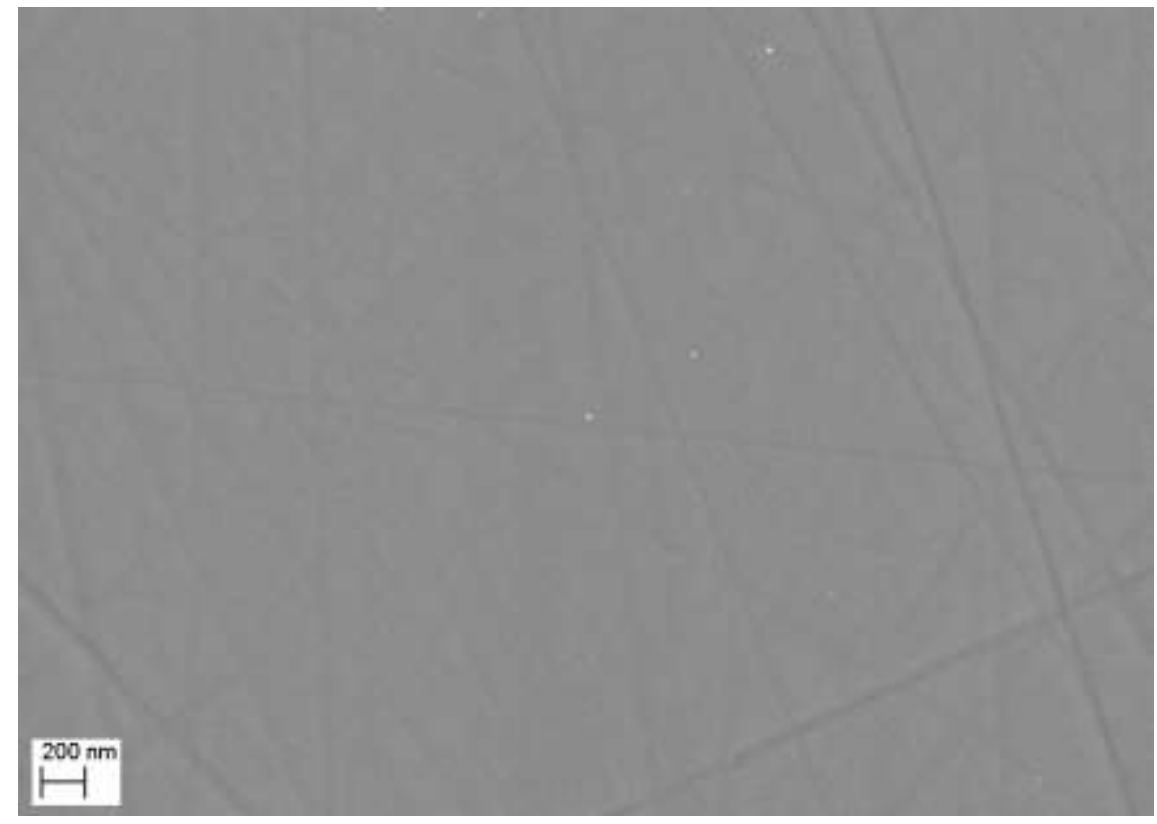

(b)

Figure 2. SEM images of (a) as-received $6 \mathrm{H}-\mathrm{SiC}$, and (b) $6 \mathrm{H}-\mathrm{SiC}$ after bombardment at room temperature by $360 \mathrm{keV} \mathrm{Cs}^{+}$ions to a fluence of $2 \times 10^{16} \mathrm{Cs}^{+} \mathrm{cm}^{-2}$. 


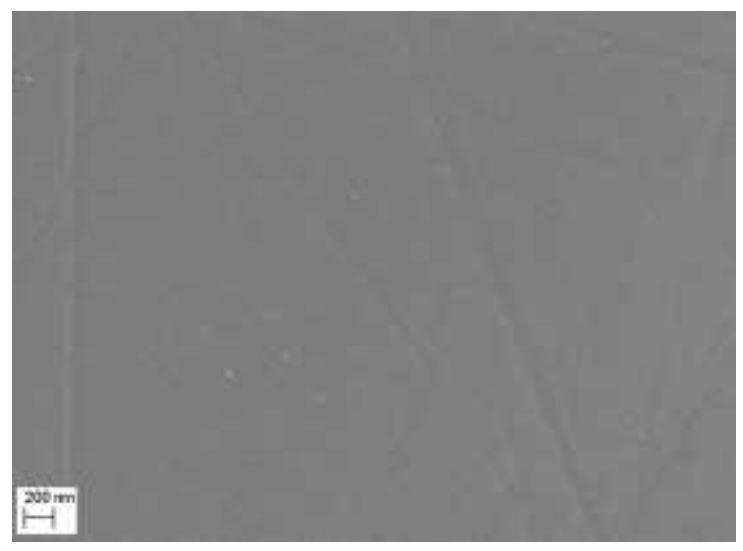

(a)

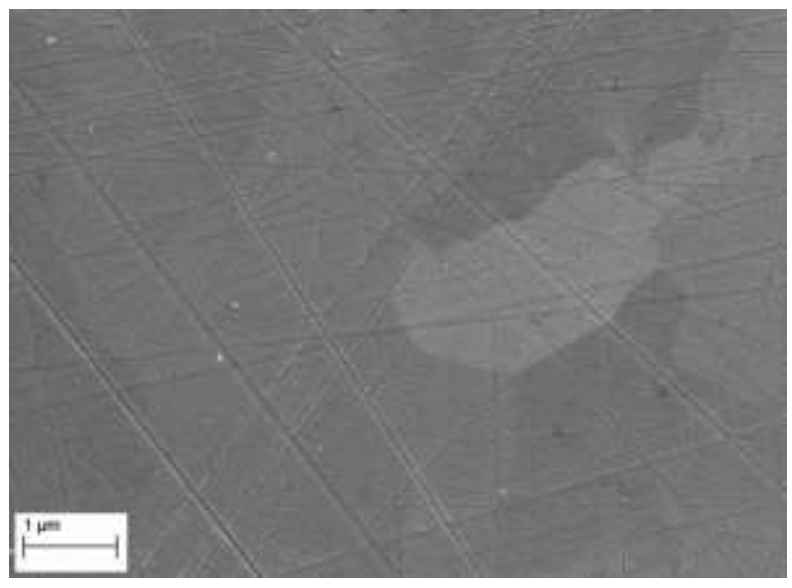

(b)

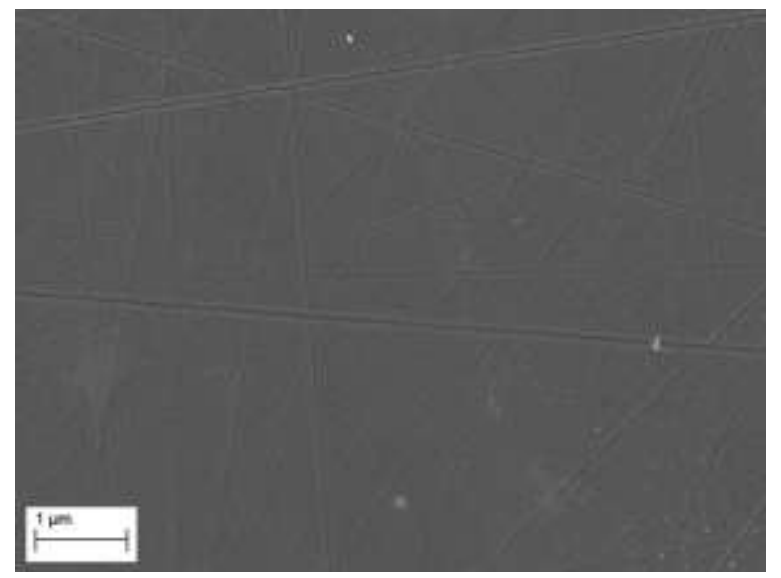

(c)

Figure 3. SEM images of polycrystalline $\mathrm{SiC}$ after bombardment with $360 \mathrm{keV} \mathrm{Cs}^{+}$ions to a fluence of $2 \mathrm{x}$ $10^{16} \mathrm{Cs}^{+} \mathrm{cm}^{-2}$ at (a) room temperature, (b) $600{ }^{\circ} \mathrm{C}$, and (b) $350{ }^{\circ} \mathrm{C}$.

It has been reported that the radiation damage occurring in $\mathrm{SiC}$ at fluences below the critical fluence for amorphization is similar between ions and neutrons at the same dpa (displacements 
per atom) value $[12,13]$. At low temperatures and low irradiation fluences the main defects are point defects (called black spot defects due to their appearances in weak beam dark field TEM images) and small interstitial clusters in various configurations. Increasing the temperature and/or fluence result in the "black spot" defects to pass into dislocations and dislocation loops. At higher temperatures and/or fluences Frank faulted loops of the interstitial type appear with $1 / 3<111>$ Burgers vectors. Voids start to appear in the $\mathrm{SiC}$ at temperatures above $1000{ }^{\circ} \mathrm{C}$ and fluences above $5 \mathrm{dpa}$. At temperatures below $350{ }^{\circ} \mathrm{C}$ and with increasing fluence the damage accumulates to eventually result in amorphization according to the direct-impact/defectstimulated model $[14,15]$. At room temperature, a fluence of about $0.5 \mathrm{dpa}$ is necessary for this. An aspect which makes radiation damage in $\mathrm{SiC}$ interesting is the fact that there is a relatively low critical temperature (approximately $350{ }^{\circ} \mathrm{C}$ ) at which amorphization cannot occur [16].

The surface effect of $360 \mathrm{keV} \mathrm{Cs}{ }^{+}$ion bombardment on $6 \mathrm{H}-\mathrm{SiC}$ can be seen in Figure 2. A typical SEM image of an as-received $6 \mathrm{H}-\mathrm{SiC}$ sample is shown in Figure 2(a). At high magnification, polishing marks on our optical flat $6 \mathrm{H}-\mathrm{SiC}$ samples are visible. After amorphization by $\mathrm{Cs}$ ion bombardment, there was a reduction in the visibility and number of polishing grooves - see Figure 2(b). This is due to two effects, i.e. swelling of the SiC due to amorphization [13] and the sputter effect of the bombarding ions, which removed the more shallow grooves. For the polycrystalline $\mathrm{SiC}$, ion bombardment at room temperature led to the same result. As can be seen in Figure 3(a) the number of polishing marks were significantly reduced. In addition, the individual grains were also no longer visible. The surfaces of the asreceived polycrystalline $\mathrm{SiC}$ samples looked very similar as the one in Figure 3(b). The latter SEM image depicts the surface of a polycrystalline $\mathrm{SiC}$ sample after bombardment with $360 \mathrm{keV}$ $\mathrm{Cs}^{+}$ions while the substrate was at $600{ }^{\circ} \mathrm{C}$ (i.e. above the critical temperature for amorphization). For these bombardment conditions (also true for other ions [3]) the grains and their boundaries were clearly visible indicating crystallinity. Although there was a reduction (due sputtering) in the number of polishing grooves, they were still clearly visible. When doing the ion bombardment at the critical temperature of $350{ }^{\circ} \mathrm{C}$, the grains were longer clearly visible indicating significant damage in the surface region (Figure 3(c)). There were some indications in the image of grains but they were not conclusive enough and addition information was necessary. This was given by RBS-channeling measurements on $6 \mathrm{H}-\mathrm{SiC}$ samples from the same wafers [9]. Implantation of $360 \mathrm{keV} \mathrm{Cs} \mathrm{ions} \mathrm{at} \mathrm{room} \mathrm{temperature,} \mathrm{amorphized} \mathrm{the} \mathrm{SiC}$ up to a depth of about $190 \mathrm{~nm}$. The crystalline structure of the $6 \mathrm{H}-\mathrm{SiC}$ was retained with $\mathrm{Cs}^{+}$bombardment at $600{ }^{\circ} \mathrm{C}$ albeit with a large number of defects. The channelling spectrum of the samples bombarded at $350{ }^{\circ} \mathrm{C}$ showed a spectrum which practically overlapped with the random spectrum indicating a highly disordered layer. This layer is not amorphous because annealing at temperatures of 1000 ${ }^{\circ} \mathrm{C}$ and higher, restored the single crystal lattice [9].

As was mentioned in the Introduction, it is hard to anneal a completely bombardmentinduced amorphous $\mathrm{SiC}$ layer on $6 \mathrm{H}-\mathrm{SiC}$ and that temperatures above $1500{ }^{\circ} \mathrm{C}$ are needed $[8,9]$. However, this does not mean that crystallites cannot form in amorphous $\mathrm{SiC}$ at much lower thermal annealing temperatures. At $900{ }^{\circ} \mathrm{C}$ crystallites on a pre-amorphized layer are visible in the SEM image shown in Figure 4. This formation of polycrystalline structures in the a-SiC layer is confirmed by a discontinuous increase in density at $900{ }^{\circ} \mathrm{C}$ [17]. Using RBS and optical methods, Wendler et al. [18] found that annealing of a-SiC even at $400{ }^{\circ} \mathrm{C}$ resulted in the layer to contain amorphized $\mathrm{SiC}$ regions with pockets of weakly damaged crystalline $\mathrm{SiC}$. These pockets of crystalline $\mathrm{SiC}$ acted as seeding points for further crystalline growth as observed at $900{ }^{\circ} \mathrm{C}$. As was shown in ref. [19] the surface crystallites, similar to the ones in Figure 4, grow in size and shape with both increasing temperature and with increasing annealing time. This solid state 


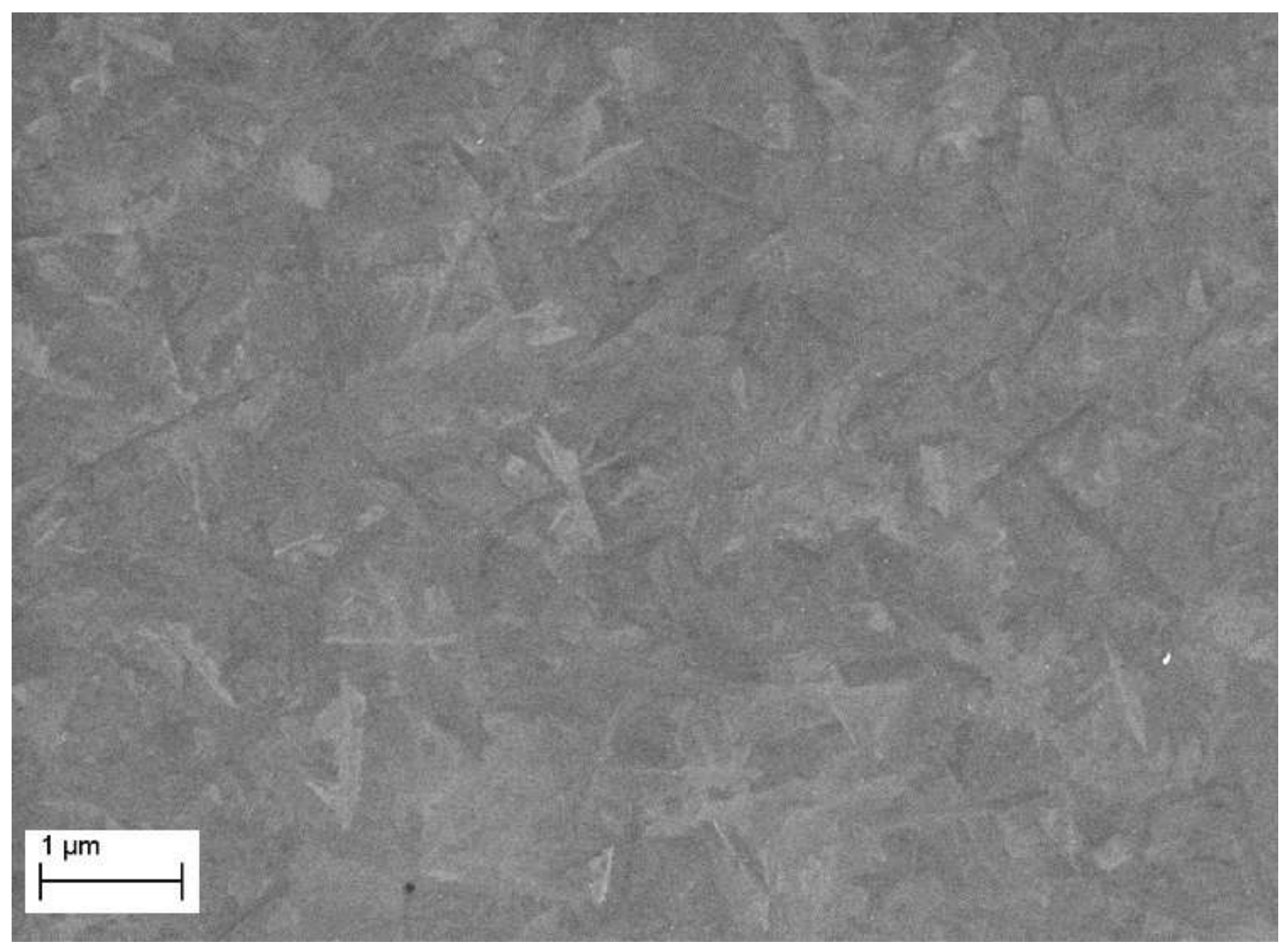

Figure 4. An in-lens SEM image showing crystallization of a $220 \mathrm{~nm}$ a-SiC layer on top of $6 \mathrm{H}-\mathrm{SiC}$ after annealing at $900{ }^{\circ} \mathrm{C}$ for $48 \mathrm{~h}$. The amorphous layer resulted from bombarding a $6 \mathrm{H}-\mathrm{SiC}$ wafer at room temperature with $360 \mathrm{keV}$ iodine ions.

crystal growth occurs according to the flow-step model of Burton et al. [20] and Frank et al. [21]. Due to this growth process the surface becomes rough with cavities occurring at higher temperatures [19]. These two features are also visible in Figures 5 to 6 . At very high annealing temperatures, i.e. $1500{ }^{\circ} \mathrm{C}$ and higher, severe thermal etching occurs, which preferentially etch certain surfaces of the crystallites away thereby reducing the crystallite sizes and eventually also the crystallites [2].

The recrystallization of the a-SiC layer on top of single crystal $6 \mathrm{H}-\mathrm{SiC}$, at the same annealing temperature and time, shows a slight dependence on the implanted atomic species [22]. As shown in Figure 5(a) a Cs implanted sample shows a fairly flat surface with small crystallites and small cavities. In contrast, the SEM image (Figure 5(b)) of an iodine implanted $\mathrm{SiC}$ sample shows much larger crystals. Some of these crystals (more clearly visible in Figure 6(a)) protrude above the surface with the top surface layer of these crystallites probably being one of the high energy surfaces of $3 \mathrm{C}$-SiC. This growth of the crystallites in the direction of their high energy surfaces, increase the area of their lower energy surfaces, thereby minimizing the total energy of the crystallites, occurs to satisfy Wulff's law [24]. The reason for the larger crystals on the iodine implanted surface is due to the beneficiation of adding small amounts of iodine to many materials, including 


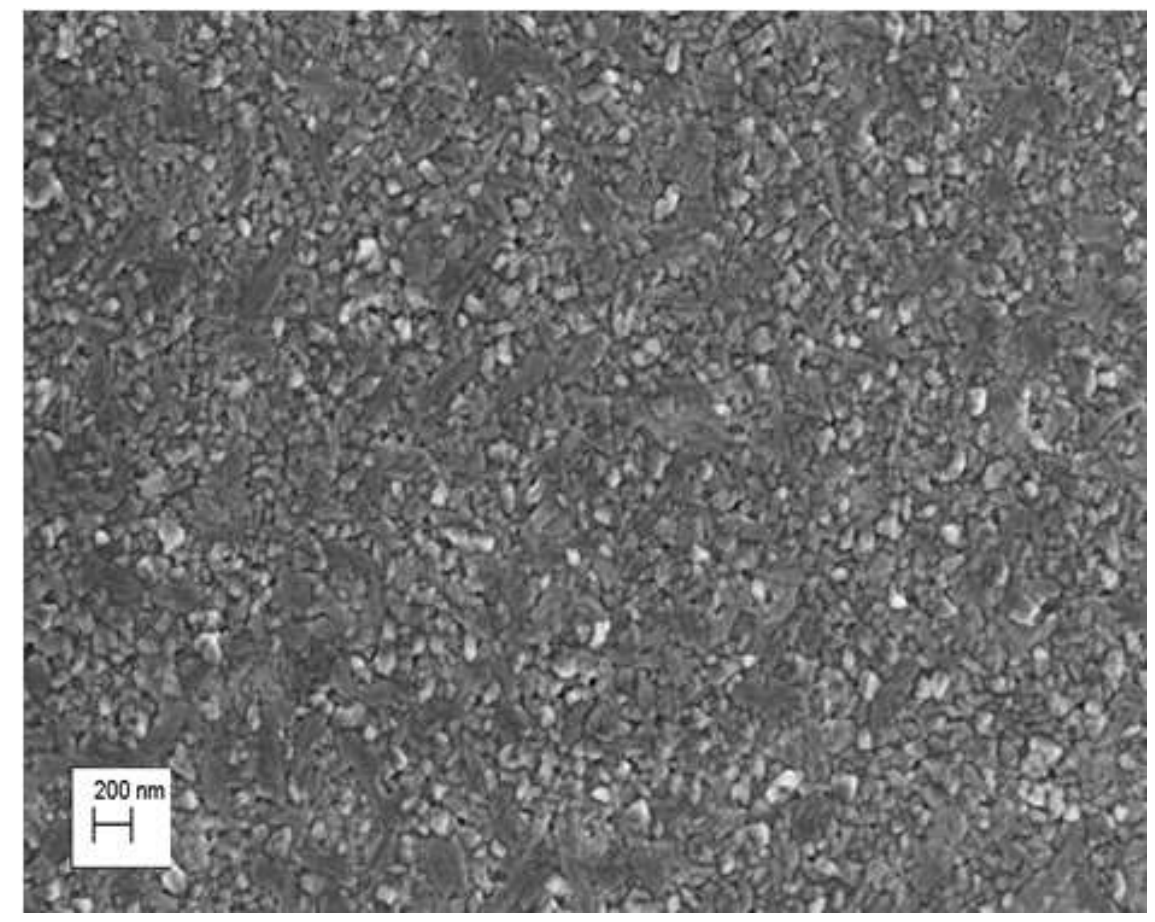

(a)

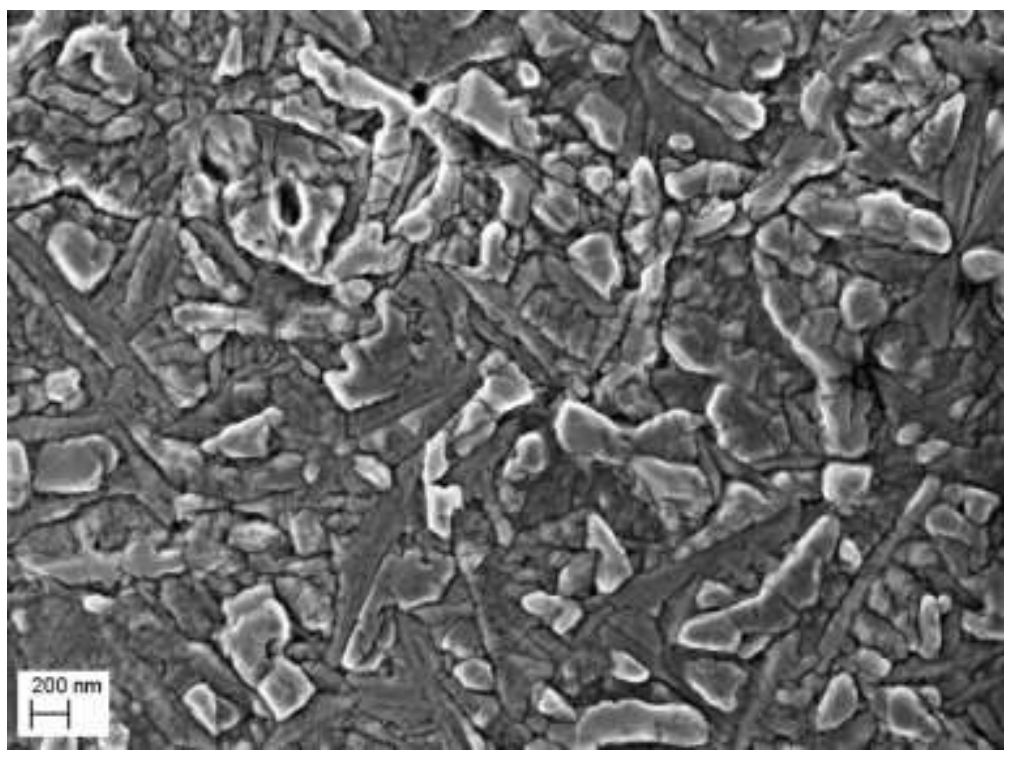

(b)

Figure 5. SEM images showing the crystallites on the originally bombardment-induced amorphous layer on top of $6 \mathrm{H}-\mathrm{SiC}$ after annealing at $1200{ }^{\circ} \mathrm{C}$ for $5 \mathrm{~h}$ in vacuum. (a) The sample was bombarded with $360 \mathrm{keV}$ $\mathrm{Cs}^{+}$ions. (b) A $360 \mathrm{keV} \mathrm{I}^{+}$sample. 


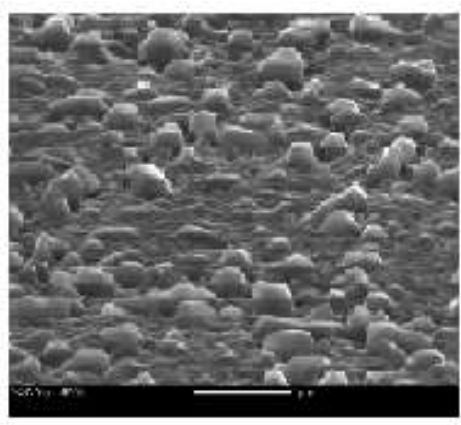

(a)

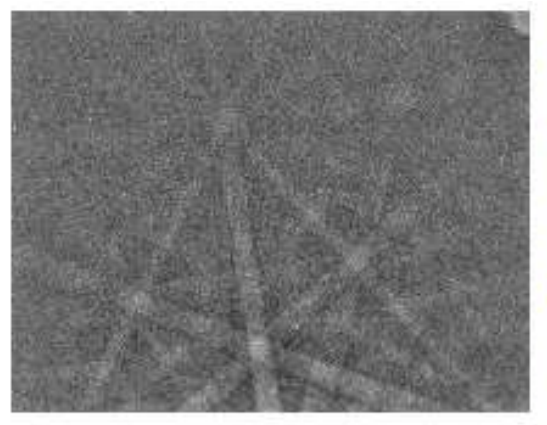

(b)

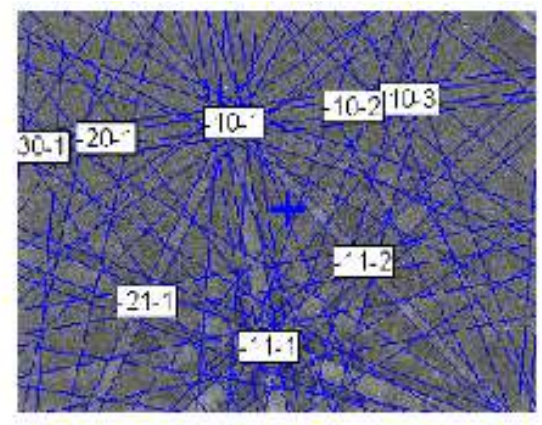

(c)

Figure 6. EBSD taken on a crystallite on the surface of a room temperature iodine bombarded single crystal $6 \mathrm{H}-\mathrm{SiC}$ wafer and then annealed at $1400{ }^{\circ} \mathrm{C}$ for $5 \mathrm{~h}$ in vacuum. (a) A $20^{\circ}$ glancing angle SEM image, taken with the normal detector, of the recrystallized surface showing several protruding crystals. Several of these crystals were analysed by EBSD. A typical EBSD analysis on one of the crystals is shown in (b) and (c). (b) A raw EBSD spectrum. (c) A computer-calculated Kikuchi-lines of the spectrum in (b).

$\mathrm{SiC}$, to grow single and polycrystalline materials - see references [3] and [19] for an expanded discussion of this topic.

An interesting question is what crystal type is formed inside and on the surface during crystallization of the ion bombardment-induced a-SiC layer on top of $6 \mathrm{H}-\mathrm{SiC}$ (or any other polytype) after thermal annealing. RBS channeling done in our laboratory (see for example results given in [3], [9], [24]) showed that after annealing above $1000{ }^{\circ} \mathrm{C}$, there was gradual epitaxial regrowth taking place from the bulk $6 \mathrm{H}-\mathrm{SiC}$, independent of ion bombardment species. Solid state epitaxial growth in the damaged layer takes place until a region, nearer to the projected range of the implanted ion, is reached where the concentration of the implanted atoms starts to hinder the epitaxial growth. During the epitaxial growth process, most of these foreign atoms in the re-grown layer are also pushed towards the surface. Both these two process increase the concentration of the foreign atoms in the amorphous layer adjacent to the newly formed epitaxial layer. This leads to a situation where increasingly longer annealing times and annealing temperatures are required for the epitaxy to continue. However, the higher and longer annealing times have the detrimental effect of thermal etching of the surface and decomposition of the SiC [2] as briefly mentioned above. At the lower temperatures and annealing times considered in this paper, the amorphous region is then free to crystallize into smaller crystallites starting from the seed crystals reported by Wendler et al. [18]. Our EBSD analyses done on $\mathrm{Ag}$ and I implanted $6 \mathrm{H}-\mathrm{SiC}$ samples showed that the surface crystallites were all $3 \mathrm{C}$ $\mathrm{SiC}$, not like the $6 \mathrm{H}-\mathrm{SiC}$ substrate. Such a result is shown in Figure 6. This seemingly contradictory result is explained in references [3] and [22] and is based on the step-flow growth modes operating in $\mathrm{SiC}$.

\section{SUMMARY}

$\mathrm{SiC}$ is a material with possible applications as the basis material for high temperature electronic devises and in the nuclear field. For both these two applications, the radiation damage properties of $\mathrm{SiC}$ need to be investigated. Traditionally, TEM (transmission electron microscopy) has been used to investigate the types of defects 
introduced in $\mathrm{SiC}$ by particle bombardment. The disadvantage of TEM is the extensive sample preparation steps needed. Thus, it is of interest to investigate how much information can be obtained using SEM (scanning electron microscopy). A very brief review is given of radiation damage in $\mathrm{SiC}$ caused by particle (ion and neutron) bombardment at different temperatures.

For this study, two substrates were used, viz. single crystalline $6 \mathrm{H}-\mathrm{SiC}$ wafers and polycrystalline $\mathrm{SiC}$, where the majority of the crystallites were $3 \mathrm{C}-\mathrm{SiC}$. The samples were bombarded by a variety of heavy ions, all with an energy of $360 \mathrm{keV}$ to a high fluence, i.e. either $1 \times 10^{16}$ or $2 \times 10^{16} \mathrm{~cm}^{-2}$. High resolution SEM was mostly used in the in-lens detection mode to characterize the surfaces of the samples. An example was given to illustrate the differences using this mode in comparison to using a normal SEM detector.

Two aspects of the effect of ion bombardment on SiC surfaces were studied. The effect of the substrate temperature on the surface morphology during bombardment was investigated at three temperatures, viz. below the critical temperature for amorphization (room temperature in this case), at (or near) this temperature, i.e. $350{ }^{\circ} \mathrm{C}$, and above the critical temperature, i.e. $600{ }^{\circ} \mathrm{C}$. Room temperature bombardment resulted in an amorphous surface structure as detected by SEM while bombardment at $600{ }^{\circ} \mathrm{C}$ resulted in the surface to remain virtually unchanged except for some layer removal due to sputtering. The morphologies of the samples bombarded at (or near) the critical temperature looked similar to the ones done at room temperature. Thermal annealing was needed to determine whether these samples were amorphized or not by the bombardment.

The second aspect investigated was the annealing of samples with an ion bombardment-induced amorphous layer on a $6 \mathrm{H}-\mathrm{SiC}$ substrate. SEM could detect that this layer started to crystalize at $900{ }^{\circ} \mathrm{C}$. The resulting topography exhibited a dependence on the ion species. EBSD showed that the crystallites forming in the amorphized layer were $3 \mathrm{C}-\mathrm{SiC}$ and not $6 \mathrm{H}-\mathrm{SiC}$ as the substrate.

\section{REFERENCES}

1. Yu. Goldberg, M. Levinshtein and S. Rumyantsev, Silicon Carbide (SiC), in M. Levinshtein, S. Rumyantsev and Shur (eds.) Properties of Advance Semiconductor Materials, Wiley, 2001.

2. N.G. van der Berg, J.B. Malherbe, A.J. Botha and E Friedland, Appl. Surf. Sci. 258 (2012) 5561.

3. J.B. Malherbe, J. Phys. D Appl. Phys. 46 (2013) 473001.

4. J.B. Malherbe, E. Friedland, N.G. van der Berg, Nucl. Instr. Methods Phys. Res. B266 (2008) 1373.

5. Group IV Elements, IV-IV and III-V Compounds. Part b - Electronic, Transport, Optical and Other Properties Landolt-Börnstein - Group III Condensed Matter Volume 41A1b, 2002.

6. P.G. Soukiassian and H.B. Enriques, J. Phys. Condens. Matter. 16 (2004) S1611.

7. P. Soukiassian and G. Dujardin, La Recherche 321 (1999) 38.

8. C.J. McHargue and J.M. Williams, Nucl. Instrum. Meth. Phys. Res. B 80/81 (1993) 889.

9. E. Friedland, N.G. van der Berg, J.B. Malherbe, J.J. Hancke, J.R.N. Barry, E. Wendler \& W. Wesch, J. Nucl. Mater. 410 (2011) 24. 
10. W. Wesh, Nucl. Instrum. Meth. Phys. Res. B 116 (1996) 305.

11.S. Limpijumnong and W.R.L. Lambrecht, Phys. Rev. B 57 (1998) 12071.

12. Y. Katoh, N. Hashimoto, S. Kondo, L. Snead and A. Kohyama, J. Nucl. Mater. 351 (2006) 228.

13.L.L. Snead, T. Nozawa, Y. Katoh, T.-S. Byun,S. Kondo and D.A. Petti, J. Nucl. Mater. 371 (2007) 329.

14. W.J. Weber, Nucl. Instrum. Meth. Phys. Res. B 166-167 (2000) 98.

15. Y. Zhang, W.J. Weber, W. Jiang, A. Hallén and G. Possnert, J. Appl. Phys. 91 (2002) 6388.

16.E. Wendler, A. Heft, W. Wesch, Nucl. Instrum. Meth. Phys. Res. B 141 (1998) 105.

17. L.L. Snead and S.J. Zinkle, Nucl. Instrum. Meth. Phys. Res. B 191 (2002) 497.

18. E. Wendler, A. Heft, W, Wesch, G. Peiter and H.H. Dunken, Nucl. Instrum. Meth. Phys. Res. B 127/128 (1997) 341.

19. J.B. Malherbe, N.G. van der Berg, A.J. Botha, E. Friedland, T.T. Hlatshwayo, R.J. Kuhudzai, E. Wendler, W. Wesch, P. Chakraborty and E.F. da Silveira, Nucl. Instrum. Methods Phys. Res. B 315 (2013) 136.

20. W. K Burton, N Cabrera and F C. Frank, Phil. Trans. Roy. Soc. 243A (1931) 299.

21. F.C. Frank and J.H. van der Merwe Proc. Royal Soc. A198 (1949) 205.

22. R.J. Kuhudzai, E. Friedland, J.B. Malherbe, C. Theron, N.G. van der Berg, T.T. Hlatshwayo, E.Wendler, W. Wesch and P. Chakraborty, Nucl. Instrum. Methods Phys. Res. B 332 (2014) 251.

23. G. Wulff, Z. Krist. 34 (1901) 449.

24. T.T. Hlatshwayo, J.B. Malherbe, N.G. van der Berg, L.C. Prinsloo, A.J. Botha, E. Wendler \& W.E. Wesch, Nucl. Instrum. Methods Phys. Res. B 274 (2012) 120. 